\title{
EMOTIONAL DEVELOPMENT AS A TASK OF EDUCATION
}

\author{
Olga Shmyreva \\ Candidate of Psychological Sciences, Associate Professor, Voronezh State University of \\ Engineering Technologies, Revolutsii street, 19, Voronezh, Russia, \\ E-mail: oishmyreva@rambler.ru
}

\begin{abstract}
The purpose of the article was to substantiate the importance of emotional development as an educational task. The need to solve a wide range of problems sets the problem of studying the potential of the individual, in which emotions play a special role. The development of emotions as a function of the psyche should become an important pedagogical task.

The phenomenon of emotional development with an emphasis on dynamic characteristics is described. Emotional development proceeds in stages. Emotion has a source of movement. The stage-by-stage process of complication and improvement of emotional forms and content, which has a driving force, characterized by determinism, consistency and complementarity of content aspects is shown.

The phased nature of the flow of emotions, the presence of a source of movement determine the intermediate and included status of emotional phenomena accompanying cognitive processes, motivation, perception and formation of values, meaning creation.

In the course of the educational process, it is necessary to progressively teach a person to develop and use the potential of emotions for solving various problems.
\end{abstract}

Keywords: emotions, emotional development, dynamic characteristics of emotions, education.

\section{INTRODUCTION}

The requirements for the formation and development of personality in a changing world are constantly becoming more complex. Education in the context of innovative transformations of society and the economy makes extensive use of technologies for influencing the psyche, since the modern digital economy is an economy of impressions. Emotions in economics are studied as a psychological basis for managing behavior; in pedagogical practice, the emotional component of the personality structure is mainly used as a means to achieve the goals of education. Given that the emotional factor plays the role of the educational process subjects' potential (Shmyreva, 2021), the emphasis should be changed to emotional development as one of the pedagogical tasks.

Emotional personality development is an aspect of the mental and is a complex multidimensional, multifactorial phenomenon that attracts the attention of scientists due to the importance of the latter for human life. Revealing the procedural characteristics of emotions will help to understand the essence of emotional development. It is known that the nature of emotions is procedural: they are fluid, genetically, mentally, socially conditioned and characterized by dynamism.

\section{METHODOLOGY}

The methodological basis of the research is made up of general scientific principles: dialectical logic (contradictions, consistency, unity of analysis and synthesis, ascent from the abstract to the concrete, 
comprehensive consideration); principles of research complexity and complementarity; empirical methods: literature analysis, comparison and grouping method, interpretation. Together, their use makes it possible, from various angles, to study the phenomenon and potential of emotional development, its dynamic characteristics, and its role in personality formation.

The theoretical basis was the work of domestic and foreign scientists who develop concepts for the improvement of personality, cognition in the educational process, the concept of cognition and emotions, the psychology of creativity.

\section{DISCUSSION}

The origin of emotions can be caused by the need for both the biological survival of the individual and the characteristics of the social functioning of a person, depending on the relationship between the motivation and the capabilities of the subject. This implies the assumption of the emotiogenic situation as the driving force of emotional development and the procedural characteristics of the latter. Any process is determined by the presence of a source of movement, which in an emotional context can be an emotiogenic situation that covers all spheres of human life. At the same time, in response to a stimulus that evokes emotions, there is the possibility of choosing one or using several strategies for regulating emotions, (Aldao, A., \& Nolen-Hoeksema, S. 2013).

Excessive motivation in relation to the real adaptive capabilities of the individual serves as an impetus for an emotiogenic situation, while there is no universal emotiogenic situation. It is known that the relationship between motivation and the subject's capabilities affects emotion, which physiologically begins with hypertonicity, the external manifestation of which is the transformation of unused energy into spasmodic movements, such as laughter, tears, and disorderly actions. If a significant situation is fixed by the mechanism of an unconditioned reflex in the genetic memory, the assessment of the significance of the latter may unconscious, of an instinctive origin, which affects the emergence of an emotional reaction.

The causation and activation of emotions are described by K.E. Izard (Izard, 2007). K.E. Izard explains determination of emotions by the types of relationships between the subject and the environment and the types of individual processes that affect the neural activation of emotions, which can be of two types. The first type characterizes the subject's emotional relationship with the environment: perception following stimulation is derived from the selective activity of a receptor or sensory organ; perception of the environment, presented primarily in the form of an orienting reflex; spontaneous perception or activity inherent in the perceiving system. The second type characterizes individual processes capable of evoking emotions: active or tested memory; imagination; figurative and anticipatory thinking; proprioceptive impulses from pantomimic or other motor activity; endocrine activity acting on the nervous or muscular mechanisms of emotions.

The psychodynamic approach was based on studies of emotional expression and associated neuroendocrine, peripheral, central processes of the nervous system, as well as on the study of cognitive, behavioral and linguistic parameters of affect. Emotions, their intrapsychic meaning and affective experiences in the psychoanalytic sense are not the result of neuronal or muscular activity.

Existential analysis explains the development and origin of emotions depending on the main feeling accompanying the experience of the basic value of the individual. The experience and perception in this capacity is associated with the basic attitude of a person to life, according to which the perception of value occurs in two stages (Langele, 2007). The first stage of the perception of value is characterized by the person's closeness to the object during direct experience, while the quality of the perceived object and its suitability for life are comprehended, while the value is associated with a specific situation and a certain time interval. Perceived at a given moment in time is not placed in the biographical plane of the personality - there are no aspects that establish distance or integration. At the second stage, the primary emotionality is integrated into the individual, felt emotional integrity, and what is appreciated as useful and good for the individual is placed in perspective. A new position in relation to value includes both rational and emotional components. The emotion underlying the position is integrative in nature and critically perceives other values that come into opposition with a spontaneously perceived value. The final position is formed through a sensual appeal to values. The image of oneself in the process of self-assessment is formed on the basis of processing emotionally colored information about oneself. It should be noted that positive information about oneself plays a special role in the formation of self-esteem (Danielsson, M., \& Bengtsson, H. 2016).

It is known that spontaneously arising primary emotions involve a person in an immanent reflection of an object and a situational ability to experience. The impression evokes an immediate response from the organism, which seeks to restore the original form, "zero position", which manifests itself as the first inner 
movement, followed by an affect or vital response. If affection leads to a deep impression, the so-called primary emotion arises. In accordance with the system of classification of phenomena characteristic of an individual, the first rough assessment of the experience appears at this level (Langle, 2007). Thus, primary experience allows one to perceive values in a semi-structured form.

The confluence of subjective and objective variables, during the interaction of which an emotion appears in the subject, serves as the basis for primary emotions. A significant amount of information is poured into the primary emotion: the structure of the personality as a readiness for feeling and spontaneous response, previous experience, the content of the impression as a message - these elements are combined into an impression, merging into a single basis of experience (Langele, 2007).

Feelings as an existential layer of the psyche mark meanings, create a biased attitude, and contribute to their translation into a personally significant meaning. We also find the same idea about the stages of emotional development, complication, improvement of emotional forms in I.P. Voropaeva: "The individual system of emotional meanings develops in ontogenesis from the emotional tone of sensations to sensory standards, then to the emotional coloring of perception images and an emotionally rich form of generalization - Personal meaning. This side of meaning-making is associated with the sphere of emotions and feelings" (Voropaeva, 2002. P. 208). Since emotions in modern culture are directly related to speech, a full-fledged emotional life is possible only under the obligatory condition - the presence of a symbolic system of language (Kolotaev, 2002).

The semiotic approach represents the formation of mechanisms of emotional response in the development of a child in the form of differentiation and sequential complication of emotions (Voropaeva, 2002), clearly demonstrating the unity of the procedural and content characteristics of emotional development. For example, during infancy, the emotional response at the beginning of life is accompanied by a cry and muscle tension of the newborn, the manifestation of a negative emotional sign in response to the beginning of the body's life. A positive state of satisfaction is manifested in peace and relaxation, by the end of the first month of life certain positive emotions appear in the form of a smile. During the first three months of life, the emotional sphere is dominated by the reactions of displeasure, crying and satisfaction (after satiety). Mimic manifestations of emotions are gradually developed, which are not only fixed in nature, but also a warning expression in the form of readiness for fear, whims, alertness, in combination with bodily expression. The mimic and pantomimic actions of the infant are of an innate and acquired signaling character. In modern conditions, the semiotic approach is being transformed and presented in an ever-increasing influence on the brain with the help of texts and text messages (Kaplunov D., 2017).

The attitude towards emotions and the choice of the situation depend on what exactly the person likes and what he is trying to get (Markovitch, N., Netzer, L., \& Tamir, M., 2017). As a primary involvement, emotion, according to $A$. Langele, with its reactive affectation, precedes more complex emotion in the form of motivation and will (Langele, 2007). There are individual differences in the motives and regulation of the intensity of affect: the positive affect of a trait or characteristic is combined with the value of the affect that is consistent with this trait (Scott H. Hemenover \& Colin R. Harbke, 2020). Consequently, the personality is gradually developing skills in the use of emotional characteristics. These observations and provisions describe the stage-by-stage process of complication and improvement of emotional forms and content, which has a driving force and is characterized by determinism, consistency and complementarity of the content aspects of emotional development.

The analysis of psychophysiological, psychodynamic, actually psychological, existential, sociocultural, semiotic approaches to the study of emotional development allows us to trace the movement in the emotional sphere in ontogenesis from emotional reactions to emotional states, emotional properties of a person and, further, to the construction of a system of relationships. It is known that emotions are present at all stages of reflective genesis, from the emotional tone of sensations to the affective-emotional coloring of perception images and object feelings (Leontyev, 1981). In the emotional "image of the world" the figurative nature of sensory reflection is fixed, the emotional image is an ideal formation as a result of the reflection of emotional experiences in emotional representations. In emotional images, on the one hand, the external picture of the environment is reflected, representing the value and meaning for the subject of objects and phenomena; on the other hand, interoceptive elements of emotional images reflect internal changes in the subject due to the existing meaning of the present situation.

Taking place in the presence of a symbolic situation, at all age stages of emotional response, a sequence of complication of mechanisms is manifested. In subsequent age periods, emotional manifestations are characterized by the differentiation and schematization of emotional generalizations characteristic of each age. 
Considering the procedural characteristics of emotional development, the author discovered the elements of staging, changeability of emotions, when this or that emotion can be the driving force of the process. In general, it becomes clear that the procedural characteristics complicate the emotional development of the personality as a system, enrich its content, making its elements more differentiated and individualized (Shmyreva, Koval, 2015). Lack of ability to perceive and analyze what is happening is due to the weakness of emotional experiences.

Since the process of personality formation is accompanied by the impact on emotions, pedagogical attention should be focused on emotional development.

\section{RESULTS}

Thus, the foregoing allows us to state that emotional development is endowed with a set of interrelated, interacting, interdependent procedural characteristics, the basis for which are psychophysiological formations: physiological mechanisms of emotions, cerebral organization of emotional phenomena, transformation of chemical processes in emotiogenic centers of the brain, the mechanism of selfreinforcement of emotions and reverse influence brain structures for emotionality. The procedural characteristics of emotional development include: the driving force of emotional development, determinism of emotional development, stages, stages of emotional development, consistency and complementarity of emotions, complication and improvement of emotional forms and content.

Analysis of information sources led to the following conclusions:

1) Emotions are a necessary component of the assessment and a resource of the intellectual sphere of a person, which can be used for cognition and building a picture of the world (Shmyreva et al., 2020).

2) The activation of mental functions of sensation, attention, memory, thinking, imagination is associated with emotions and affects behavior, perception, participation in information processing (Shmyreva, \& Sova, 2020).

3) The preference for familiar emotions is formed on the basis of experience (Ford, \& Tamir, 2014), it is possible to use several strategies for regulating emotions, in response to a stimulus that evokes emotions (Aldao, A., \& Nolen-Hoeksema, S. 2013), while attitudes towards emotions and the choice of a situation is determined by a positive assessment of what efforts are directed at (Scott $\mathrm{H}$. Hemenover \& Colin R. Harbke, 2020).

4) Interpretation at the contemplative-explanatory stage, both in the creative process and in the course of solving various problems, includes the assessment of objects and phenomena (Shmyreva, 2020).

5) The emotional factor acts as the potential of the subjects of the educational process (Shmyreva, 2021).

\section{CONCLUSION}

Emotional development of a person, regardless of changing conditions, should remain one of the tasks of education, be of immeasurably greater value in any society wishing to prosper than technology and artificial intelligence. Emotions form a worldview, participate in the intellectual processes of cognition, assessment, creativity, involvement in communication and activities, the formation of meanings and values. Relying on the emotional potential of the individual in the course of performing various types of activities will reduce the risks of erroneous actions and conclusions.

The influence of emotions on value perception, their involvement in the processes of motivation and will, necessitate attention to them as a leading factor in personality development. Increasing the ability to use emotions to solve problems should be carried out continuously in the course of the educational process, starting from an early age and throughout the entire period of personality formation.

\section{REFERENCE LIST}

Ababkova M. (2017). Neuromarketing technologies in education. Moscow: Foundation for the Development of Conflictology. 290 p. (in Russ).

Aldao, A., \& Nolen-Hoeksema, S. (2013). One versus many: Capturing the use of multiple emotion regulation strategies in response to an emotion-eliciting stimulus. Cognition and Emotion, 27. Pp. 753-760. DOI: 
https://doi.org/10.1080/02699931.2012.739998 (in Engl).

Ashmarov I.A., Ershov B.A. (2019) The role of Russian spiritual education in the formation of culture in a secular society of the XIXth - early XXth centuries. The Border Region in Historical Development: Partnership and Cooperation. Materials of the international scientific-practical conference dedicated to the 80th anniversary of the Victory of the Soviet and Mongolian troops on the Khalkhin-Gol river. Chita: Publisher: Transbaikal State University. Pp. 50-53. (in Russ).

Ashmarov I.A., Volkova E.A., Frolova E.V. (2015) To the Question of Formation of Trends in the Higher Education System within the Framework of Modern Globalization Processes. Modern problems of science and education. №. 1-1. P. 975. (in Russ).

Danielsson, M., \& Bengtsson, H. (2016). Global self-esteem and the processing of positive information about the self. Personality and Individual Differences, 99. Pp. 325-330. DOI: https://doi.org/10.1016/j.paid.2016.05.014 (in Engl).

Ershov B.A. (2010) The Russian Orthodox Church and secular power in the Voronezh province in the XIX early XX centuries. GOU VPO "Voronezh State Technical University". Voronezh. 167 p. (in Russ).

Ershov B.A. (2010) The system of spiritual education in Voronezh province in the 19th century. Education and Society. №. 5 (64). Pp. 105-108. (in Russ).

Ershov B.A., Fursov V.N. (2018) The Russian Church in the State Mechanism of Russia. Bulletin SocialEconomic and Humanitarian Research. № 1. Pp. 32-37. (in Engl).

Ershov B.A., Perevozchikova L.S., Romanova E.V. (2019) Globalization and Intensification of Spiritual Values in Russia in the Philosophical Aspect. 6th International Conference on Education and Social Sciences Abstracts \& Proceedings. Pp. 208-212. (in Engl).

Ershov B.A., Perevozchikova L.S., Romanova E.V., Ashmarov I.A. (2019) The Concept of Spirituality in Social Philosophy. Smart Innovation, Systems and Technologies. T. 139. Pp. 688-694. (in Engl).

Ford, B.Q., \& Tamir, M. (2014). Preferring familiar emotions: As you want (and like) it? Cognition and emotion. Vol. 28. Issue 2. Pp. 311-324. DOI: https://doi.org/10.1080/02699931.2013.823381 (in Engl).

https://doi.org/10.51508/intcess.2021193 (In Turkey).

Izard, K.E. (2007). Psychology of emotions. SPb .: Peter. 464 p. (in Russ).

Kaplunov D. (2017). Neurocopywriting. 100 methods of influence with the help of text. M: Publishing house "E". 352 p. (in Russ).

Kolotaev, V.A. (2002). The problem of the relationship between emotionality and the language of culture (based on Haneke's film "The Pianist"). World of Psychology, 4 (32), Pp. S. 171 - 178 (in Russ).

Langle, A. (2007). Emotions and Existence. Kh .: Publishing House of the Humanitarian Center. 332 p. (in Russ).

Leontiev, A.N. (1981). On the mechanism of sensual reflection // Problems of the development of the psyche. 2nd ed. Moscow. Pp. 161 - 192. (in Russ).

Markovitch, N., Netzer, L., \& Tamir, M. (2017). What you like is what you try to get: Attitudes toward emotions and situation selection. Emotion, 17(4). Pp. 728-739. DOI: https://doi.org/10.1037/emo0000272 (in Engl).

Scott H. Hemenover \& Colin R. Harbke. (2020). Individual differences in motives for regulating affect intensity: positive trait affect and the value of trait-consistent affect. Cognition and emotion, Vol. 28. DOI: https://doi.org/10.1007/s11031-020-09844-4 (in Engl).

Shmyreva O. (2020) Transformation of emotions into creatiyity as a way of solving problems. Revista Inclusiones. Volumen 7. - Numero Especial. - Octubre / Diciembre 2020. Pp. 464 - 476. (In Chile).

Shmyreva O. (2021). Education, information ethics and emotion during the development of the digital economy. Proceedings of INTCESS 2021 8th INTERNATIONAL CONFERENCE ON EDUCATION AND EDUCATION OF SOCIAL SCIENCES. Istanbul, January 18-19, 2021. Abstracts \& Proceedings. 2021. International Organization Center of Academic Research. Istanbul. 2021. Pp. 484 - 488. (ISBN: 978-605-06286-1-6).

Shmyreva O.I., Chernigovskikh I.V., Ponomareva E.Y. (2020). Information Ethics as a Factor in the 
Development of the Digital Economy. Proceedings of the Russian Conference on Digital Economy and Knowledge Management. Series: "Advances in Economics, Business and Management Research». Atlantis Press. https://dx.doi.org/10.2991/aebmr.k.200730.112 (in Engl).

Shmyreva O.I., Sova A.N. (2020). Behavior Management Based on Psychological Services. II International Scientific and Practical Conference on Digital Economy (ISCDE 2020). Series: «Advances in Economics, Business and Management Reseach». Atlantis Press. https://dx.doi.org/10.2991/aebmr.k.201205.117

Shmyreva, O.I., Koval N.A. (2015). Process and contentin the emotional development. World of Psychology, 3 (83), Pp. 207 - 216. (in Russ).

Voropaeva I.P. (2002). Emotions and pedagogical potential of semiotics. World of Psychology, 4 (32), Pp. 203 - 209. (in Russ). 